\title{
The effect of temperature, gradient, and load carriage on oxygen consumption, posture, and gait characteristics
}

\author{
Katrina Hinde $^{1}\left(\mathbb{D} \cdot\right.$ Ray Lloyd $^{2} \cdot$ Chris Low $^{1} \cdot$ Carlton Cooke $^{2}$
}

Received: 5 May 2016 / Accepted: 29 December 2016 / Published online: 2 February 2017

(C) The Author(s) 2017. This article is published with open access at Springerlink.com

\begin{abstract}
Purpose The purpose of this experiment was to evaluate the effect of load carriage in a range of temperatures to establish the interaction between cold exposure, the magnitude of change from unloaded to loaded walking and gradient.

Methods Eleven participants (19-27 years) provided written informed consent before performing six randomly ordered walking trials in six temperatures $(20,10,5,0,-5$, and $\left.-10^{\circ} \mathrm{C}\right)$. Trials involved two unloaded walking bouts before and after loaded walking $(18.2 \mathrm{~kg})$ at $4 \mathrm{~km} \cdot \mathrm{h}^{-1}$, on 0 and $10 \%$ gradients in 4 min bouts.

Results The change in absolute oxygen consumption $\left(\mathrm{VO}_{2}\right)$ from the first unloaded bout to loaded walking was similar across all six temperatures. When repeating the second unloaded bout, $\mathrm{VO}_{2}$ at both -5 and $-10^{\circ} \mathrm{C}$ was greater compared to the first. At $-10^{\circ} \mathrm{C}, \mathrm{VO}_{2}$ was increased from $1.60 \pm 0.30$ to $1.89 \pm 0.51 \mathrm{~L} \cdot \mathrm{min}^{-1}$. Regardless of temperature, gradient had a greater effect on $\mathrm{VO}_{2}$ and heart rate (HR) than backpack load. HR was unaffected by temperature. Stride length (SL) decreased with decreasing temperature, but trunk forward lean was greater during cold exposure.

Conclusion Decreased ambient temperature did not influence the magnitude of change in $\mathrm{VO}_{2}$ from unloaded to loaded walking. However, in cold temperatures, $\mathrm{VO}_{2}$ was
\end{abstract}

Communicated by George Havenith.

Katrina Hinde

k.hinde@leedsbeckett.ac.uk

1 Leeds Beckett University, Headingley Campus, Leeds, West Yorkshire LS6 3QS, UK

2 Leeds Trinity University, Brownberrie Lane, Horsforth, Leeds LS18 5HD, UK significantly higher than in warm conditions. The increased $\mathrm{VO}_{2}$ in colder temperatures at the same exercise intensity is predicted to ultimately lead to earlier onset of fatigue and cessation of exercise. These results highlight the need to consider both appropriate clothing and fitness during cold exposure.

Keywords Load carriage $\cdot$ Cold exposure $\cdot$ Oxygen consumption $\cdot$ Stride length

$\begin{array}{ll}\text { Abbreviations } \\ \text { ANOVA } & \text { Analysis of variance } \\ \text { BAT } & \text { Brown adipose tissue } \\ \text { HR } & \text { Heart rate } \\ \text { MST } & \text { Mean skin temperature } \\ \text { NST } & \text { Non-shivering thermogenesis } \\ \text { VO }_{2} & \text { Oxygen consumption } \\ \text { SL } & \text { Stride length } \\ \text { TFL } & \text { Trunk forward lean }\end{array}$

\section{Introduction}

Recreational trekking and mountaineering is becoming increasingly popular and affordable and activities, such as these, alongside numerous occupational tasks, usually require external loads to be carried. Loads can be carried in various ways, but in mountaineering, trekking and military operations, the backpack is recommended as the most versatile, appropriate, and economical method of manual load carriage (Knapik et al. 1996). The relationship between load carried and energy expenditure has been extensively researched. The general consensus regarding energy expenditure when carrying loads on the back is that as load increases, oxygen consumption and 
thus energy expenditure increase in an approximately proportional manner (Quesada et al. 2000; Lloyd and Cooke 2000; Faghy and Brown 2014). However, new evidence suggests that during very heavy load carriage (up to $45 \mathrm{~kg})$, the increases in oxygen consumption $\left(\mathrm{VO}_{2}\right)$ are not proportional to the load mass (Phillips et al. 2016a). The energy cost of carrying such loads not only depends on the weight of the load, but also varies depending on the age, ethnicity, body mass of the participant, speed, terrain, and biomechanical factors (Givoni and Goldman 1971; Hainsman 1988; Phillips et al. 2016b).

It has been widely reported that $\mathrm{VO}_{2}$ increases during submaximal exercise in the cold compared to a moderate ambient temperature (Sandsund et al. 1998; Oksa et al. 2004; Jett et al. 2006). Doubt (1991) concluded that there were two possible reasons for higher exercise $\mathrm{VO}_{2}$ in the cold. The first is non-exercising thermogenesis (shivering), and in the absence of shivering, an elevated $\mathrm{VO}_{2}$ suggests non-shivering thermogenesis (NST). NST, a facultative form of thermogenesis, includes muscle tensing, feeling of stiffness and enhanced metabolism (Parsons 2003) being closely linked with brown adipose tissue (BAT) activity (Nedergaard et al. 2007). It is unknown at what environmental temperatures, NST becomes active. The second mechanism, not independent from the first, for higher exercise $\mathrm{VO}_{2}$ in the cold is the potential decrease in mechanical efficiency (Doubt 1991; Oksa et al. 2004).

There is considerable literature surrounding load carriage, but most of this work is laboratory based in thermoneutral environments. There is little known about the interactive effects of cold exposure and load carriage which is surprising given both factors are commonly experienced together. The literature surrounding cold exposure mainly focuses on cycling performance and a comparison between two temperatures (warm and cold), although some studies compare three temperatures. There have only been two other investigations using a range of six ambient temperatures (Sandsund et al. 2012; Renberg et al. 2014), but these were concerned with running performance, employing higher exercise intensities $\left(67-100 \% \mathrm{VO}_{2 \max }\right)$ with participants wearing adequate winter (ski) clothing. This is the first investigation into the effects of a range of decreasing temperatures on physiological variables during walking. In addition, there are very few studies assessing the effect of temperature on biomechanical variables, in particular, stride parameters. Limited evidence suggests that cold exposure elicits an increase in stride frequency and a decrease in stride length (SL, Folland et al. 2006). Furthermore, there are equivocal findings associated with stride parameters and walking on a gradient. Much of the existing literature involves studies that focus solely on the biomechanical or physiological effects of load carriage, with very few taking a combined factor approach (Simpson et al. 2011), ignoring the reality that such effects can interact.

The purpose of the present study was to investigate the effect of load carriage in a range of temperatures to establish the interaction between cold exposure and the magnitude of change from unloaded to loaded walking when studying $\mathrm{VO}_{2}$, heart rate (HR) and skin temperature. In addition, the interaction between gradient and load was evaluated to establish which stressor has a greater effect on oxygen consumption and whether the combined effect is equal to, less than or greater than the individual stressors.

We hypothesised that oxygen consumption would increase as temperature decreased and thus the change in $\mathrm{VO}_{2}$ when going from unloaded to loaded walking would be greater during cold exposure. Skin temperature and, therefore, HR would be significantly reduced during cold exposure. It was also hypothesised that a combination of increased gradient, load and decreased temperature would all interact to create a greater associated oxygen consumption and increases in SL.

\section{Methods}

\section{Participants}

University students ( $n=11$; seven males, four females) volunteered to participate in the study (age, $22 \pm 3$ years; height, $173.9 \pm 8.6 \mathrm{~cm}$; body mass, $71.31 \pm 10.44 \mathrm{~kg}$ ). The experimental procedures were approved by the Local Research Ethics Committee of the Carnegie Faculty at Leeds Beckett University. Prior to testing, participants were all informed of the procedures and potential risks of the experiments. All participants gave written informed consent.

Participants were apparently healthy, aged 18+ years and assessed as "low-risk" individuals by the ACSM (2013) Guidelines for cardiovascular, pulmonary, and metabolic diseases. If after answering questions on risk factors, signs, symptoms, and history of disease, participants had no risk factors or a maximum of one then they were classed as low risk. Areas assessed for risk factors were age, family history, smoking status, lifestyle, obesity, and hypertension. Participants were habitually active, completing 3-5 sessions of moderate exercise a week and were able to easily tolerate $2 \mathrm{~h}$ of submaximal exercise relative to their fitness levels.

\section{Exercise protocol}

A short exercise protocol of $\sim 50 \mathrm{~min}$ (involving $24 \mathrm{~min}$ of walking) was completed in an environmental chamber (TISS, Peak Performance Chamber Series 2009, 
Hampshire, UK) at Leeds Beckett University. Environmental conditions were kept constant and controlled at $50 \pm 5 \%$ humidity, $\sim 160 \mathrm{mmHg}$ partial pressure of oxygen and with a wind speed of $2.9 \mathrm{~m} \cdot \mathrm{s}^{-1}$. Participants completed six trials, one at each temperature $(20 \pm 0.5,10 \pm 0.5,5 \pm 0.5$, $0 \pm 0.5,-5 \pm 0.5$, and $\left.-10 \pm 1.0^{\circ} \mathrm{C}\right)$. Participants' exposure to the different environmental temperatures was assigned using a Counter-balanced Latin square and at least $24 \mathrm{~h}$ separated trials. Participants wore shorts, t-shirt, and trainers for all trials, and for trials at $0^{\circ} \mathrm{C}$ and below, hat and gloves were worn.

Before any exercise took place, participant's resting blood pressure and resting heart rate were measured to ensure that they were apparently healthy and safe to test. Resting blood pressure was measured using the Boso Medicus (Bosch, Jungingen, Germany) manual blood pressure device, whilst resting heart rate was measured using a Polar T31 coded ${ }^{\mathrm{TM}}$ transmitter and FT1 watch (Polar, Kempele, Finland). Values for blood pressure of $<140 / 90 \mathrm{mmHg}$ were accepted as normal, as were resting HR values of $<100$ beats $\cdot \min ^{-1}$. Baseline skin temperature was also measured using a Squirrel Data Logger (400 Series: 401/451, Wessex Power, Dorset, UK). Skin temperature was measured at four sites (chest, forearm, thigh, and calf), and mean skin temperature (MST) was calculated using the equation created by Ramanathan (1964): $\mathrm{MST}=[0.3$ (chest + arm $)]+[0.2($ thigh + leg $)]$.

The protocol began with a 15-min standardised rest period during which heart rate and skin temperature were measured. Core temperature during $-10^{\circ} \mathrm{C}$ exposure was measured using an ingestible CorTemp ${ }^{\circledR}$ pill (HQInc, Palmetto, Florida) for safety reasons and to ensure that core temperature did not drop below $35.5^{\circ} \mathrm{C}$. Participants then performed unloaded walking on a calibrated treadmill (PPS-med 1, Woodway, Weil am Rhein, Germany) at $4 \mathrm{~km} \cdot \mathrm{h}^{-1}$ for $4 \mathrm{~min}$ bouts at 0 and $10 \%$ gradient. $1 \mathrm{~min}$ was given after walking at $0 \%$ for the treadmill to increase to $10 \%$ grade, during which the participant was stationary. Following a rest period allowing for heart rate to return to resting level $(7.05 \pm 1.55 \mathrm{~min})$, the same walking trial was completed; however, this time participants were loaded, carrying an $18.2 \mathrm{~kg}$ backpack. Another rest period was set $(6.31 \pm 1.58 \mathrm{~min})$ followed by the unloaded section being repeated again. An exercise duration of $4 \mathrm{~min}$ was chosen as previous studies by Lloyd and Cooke (2000) have shown that $3 \mathrm{~min}$ of exercise is sufficient for participants to be walking to achieve steady-state oxygen consumption. The authors can confirm that steady-state $\mathrm{VO}_{2}$ was achieved and there were no significant differences between the third and last minute $\mathrm{VO}_{2}$ readings for any of the environmental conditions.

Heart rate (HR) was monitored continuously throughout the protocol and averaged over the last minute of each stage. Expired gas was analysed by an online gas analyser (Cortex 3B Metalyzer, Leipzig, Germany). Data were collected breath-by-breath, but evaluated over $30 \mathrm{~s}$ intervals. Reported $\mathrm{VO}_{2}$ data were calculated from the last minute of each stage. Participants wore a facemask attached to the sample line which was connected to the online gas analyser. Calibration of the online system was performed before each trial, and values were accepted if the offset was within $0.02 \%$ of the actual concentrations.

Participants were filmed from the side using a standard video camera (Casio EX-FH100, New Jersey, USA) set at $60 \mathrm{~Hz}$. The camera was set up $2.58 \pm 0.03 \mathrm{~m}$ from the treadmill and perpendicular to the treadmill belt. A calibration frame was set up and recorded before each participant began a trial. Biomechanical data were collected in the last minute of each exercise bout for $10 \mathrm{~s}$. Comparable to Lloyd and Cooke (2011), three of the events that occur during a single gait cycle were chosen for analysis: heel strike, mid support, and toe-off. Data were analysed using SIMI Motion 8.5.6 (Unterschleissheim, Germany). Stride length (SL) was calculated using the video recordings according to Lloyd and Cooke (2011). A stride was defined as the period between consecutive toe-off events of the left foot. The time taken for six complete strides (12 steps) was measured and then divided by 6 to get cycle time in seconds (Levine et al. 2012). SL was calculated by multiplying the known treadmill speed $\left(1.1 \mathrm{~m} \cdot \mathrm{s}^{-1}\right)$ by cycle time. Two landmarks (left hip and left shoulder) were identified using markers. Trunk forward lean included three measurements during a randomly selected, complete gait cycle within the $10 \mathrm{~s}$ filming period: left heel strike, mid support, and toe-off. An angle of greater than $90^{\circ}$ indicated trunk forward lean and angles less than $90^{\circ}$ showed backwards inclination.

\section{Study design}

\section{Walking speed}

A walking speed of $4 \mathrm{~km} \cdot \mathrm{h}^{-1}$ was selected due to the consistency of its use within load carriage research and its economy in normal adult walking compared to higher or lower speeds (Grenier et al. 2011).

\section{Temperature}

A control temperature of $20^{\circ} \mathrm{C}$ was selected as the highest temperature as it is often reported within the literature (Oksa et al. 2004). The majority of studies employed cycling as their exercise modality and usually only focused on one cold temperature against a control. The selection of $-10^{\circ} \mathrm{C}$ as the lowest temperature was based on a balance of considerations of commonly experienced temperatures in popular trekking/mountaineering areas (OnTop 2014), a 
range of temperatures used in previous studies investigating cold air exposure (Timmons et al. 1985; Oksa et al. 2004) and tolerance and discomfort of participants for $1 \mathrm{~h}$ wearing minimal clothing.

\section{Load}

The load carried was made up of items usually taken on trekking/mountaineering trips. One backpack (Wynnster Equador) was used for the whole study and for all participants. The backpack had a $65 \mathrm{~L}$ capacity and was fitted to each participant before their trial started. The adjustable ladder on the main section of the backpack was altered depending on participants' height and participants were encouraged to carry the majority of the weight on their hips rather than the shoulders. The weight of the loaded pack was $18.2 \mathrm{~kg}$ with load justification coming from a combination of previous research methodologies (Simpson et al. 2011).

\section{Statistical analysis}

Data were analysed using IBM SPSS 22, with significance tested at $95 \%$ confidence intervals (CI), $p<0.05$. Descriptive statistics $($ mean $\pm \mathrm{SD})$ were calculated for all outcome measures. All data were tested for normality (Shapiro-Wilk), and all data were normally distributed $(p>0.05)$. To assess for differences between conditions, threeway repeated measures analysis of variance (ANOVA) $(6 \times 3 \times 2$; temperature $\times$ load $\times$ gradient $)$ was conducted to establish any significant main effects and interactions, accounting for variability across the whole study. This analysis was followed up with three-way repeated measures ANOVAs $(6 \times 2 \times 2$; temperature $\times$ load $\times$ gradient $)$ which separated the loading conditions to allow the separate research questions to be addressed (i.e., unloaded 1, loaded; unloaded 1 and unloaded 2; unloaded 2, loaded).
Post-hoc tests for significant main effects were conducted using a Bonferroni adjustment. Change in $\mathrm{VO}_{2}\left(\mathrm{~L} \cdot \mathrm{min}^{-1}\right)$ from unloaded to loaded walking $\left(\Delta \mathrm{VO}_{2}\right)$ was analysed using a two-way repeated measures ANOVA $(6 \times 2$; temperature $\times$ gradient). Mean skin temperature was analysed in a similar way $(6 \times 6$, temperature $\times$ time $)$. In cases when the assumption of sphericity was violated, the Huynh-Feldt correction was used. Effect sizes for repeated measures ANOVA were calculated using partial eta squared $\left(\eta_{\mathrm{p}}^{2}\right)$. Two-way and three-way interactions were reported, and classification of interactions were identified according to Lloyd and Havenith (2016).

\section{Results}

\section{Oxygen consumption}

\section{Effect of individual stressors}

Variation in oxygen consumption across all experimental conditions is shown in Table 1. As ambient temperature decreased, $\mathrm{VO}_{2}$ significantly increased $(p<0.001$, $\left.\eta_{\mathrm{p}}{ }^{2}=0.460\right)$. Post-hoc tests identified a number of significant differences between ambient temperatures averaged across all loads and gradients ( $p \leq 0.045$, Fig. 1).

The repeated unloaded bout of exercise was included to assess variation in low intensity walking and the potential effect of fatigue. When analysing both unloaded conditions, there was a significant main effect for load $(p=0.028$, $\left.\eta_{\mathrm{p}}{ }^{2}=0.397\right)$, with unloaded 2 producing significantly higher $\mathrm{VO}_{2}$ values than unloaded 1 .

The increase in $\mathrm{VO}_{2}$ from unloaded to loaded walking did not change significantly with temperature $\left(\Delta \mathrm{VO}_{2}\right.$, $p=0.44, \eta_{\mathrm{p}}{ }^{2}=0.089$ ). Although $\mathrm{VO}_{2}$ was significantly higher when walking uphill $(10 \%)$, the changes in $\mathrm{VO}_{2}$
Table 1 Mean $\pm \mathrm{SD} \mathrm{VO}_{2}$ $\left(\mathrm{L} \cdot \mathrm{min}^{-1}\right)$ values for each temperature, load, and gradien

\begin{tabular}{|c|c|c|c|c|c|c|}
\hline & \multicolumn{2}{|l|}{ Unloaded 1} & \multicolumn{2}{|l|}{ Loaded } & \multicolumn{2}{|l|}{ Unloaded 2} \\
\hline & $0 \%$ & $10 \%$ & $0 \%$ & $10 \%$ & $0 \%$ & $10 \%$ \\
\hline $20^{\circ} \mathrm{C}$ & $0.97 \pm 0.18$ & $1.65 \pm 0.30^{\mathrm{e}}$ & $1.14 \pm 0.18^{\mathrm{d}}$ & $1.99 \pm 0.29^{\mathrm{de}}$ & $0.95 \pm 0.17$ & $1.65 \pm 0.28^{\mathrm{e}}$ \\
\hline $10^{\circ} \mathrm{C}$ & $1.03 \pm 0.15$ & $1.78 \pm 0.28^{\mathrm{e}}$ & $1.23 \pm 0.21^{\mathrm{d}}$ & $2.17 \pm 0.30^{\mathrm{de}}$ & $1.01 \pm 0.13$ & $1.78 \pm 0.28^{\mathrm{e}}$ \\
\hline $5^{\circ} \mathrm{C}$ & $1.05 \pm 0.19$ & $1.70 \pm 0.27^{\mathrm{e}}$ & $1.24 \pm 0.25^{\mathrm{d}}$ & $2.09 \pm 0.37^{\mathrm{de}}$ & $1.10 \pm 0.21$ & $1.74 \pm 0.31^{\mathrm{e}}$ \\
\hline $0^{\circ} \mathrm{C}$ & $1.05 \pm 0.20$ & $1.74 \pm 0.24^{\mathrm{e}}$ & $1.30 \pm 0.16^{\mathrm{d}}$ & $2.14 \pm 0.28^{\mathrm{de}}$ & $1.25 \pm 0.38$ & $1.80 \pm 0.29^{\mathrm{e}}$ \\
\hline$-5^{\circ} \mathrm{C}$ & $1.24 \pm 0.16^{\mathrm{abc}}$ & $2.00 \pm 0.32^{\text {abce }}$ & $1.47 \pm 0.27^{\mathrm{abcd}}$ & $2.34 \pm 0.29^{\mathrm{abcde}}$ & $1.56 \pm 0.36^{\mathrm{abc}}$ & $2.23 \pm 0.32^{\text {abce }}$ \\
\hline$-10^{\circ} \mathrm{C}$ & $1.21 \pm 0.21^{\mathrm{a}}$ & $1.99 \pm 0.46^{\mathrm{ae}}$ & $1.61 \pm 0.40^{\mathrm{ad}}$ & $2.35 \pm 0.59^{\text {ade }}$ & $1.59 \pm 0.42^{\mathrm{a}}$ & $2.20 \pm 0.62^{\mathrm{ae}}$ \\
\hline
\end{tabular}

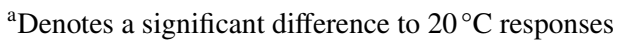

${ }^{b}$ Denotes a significant difference to $10^{\circ} \mathrm{C}$ responses

${ }^{\mathrm{c}}$ Denotes a significant difference to $0^{\circ} \mathrm{C}$ responses

${ }^{\mathrm{d}}$ Denotes a significant difference to unloaded responses

${ }^{\mathrm{e}}$ Denotes a significant difference to $0 \%$ responses 
Fig. 1 Mean $+\mathrm{SD} \mathrm{VO}$ values $\left(\mathrm{L} \cdot \mathrm{min}^{-1}\right)$ and $\mathrm{HR}$ (beats $\cdot \min ^{-1}$ ) for the different ambient temperatures averaged across all gradients and loads, asterisk denotes a significant difference to $20^{\circ} \mathrm{C}$, dagger denotes a significant difference to $10^{\circ} \mathrm{C}$, and section symbol denotes a significant difference to $0^{\circ} \mathrm{C}$

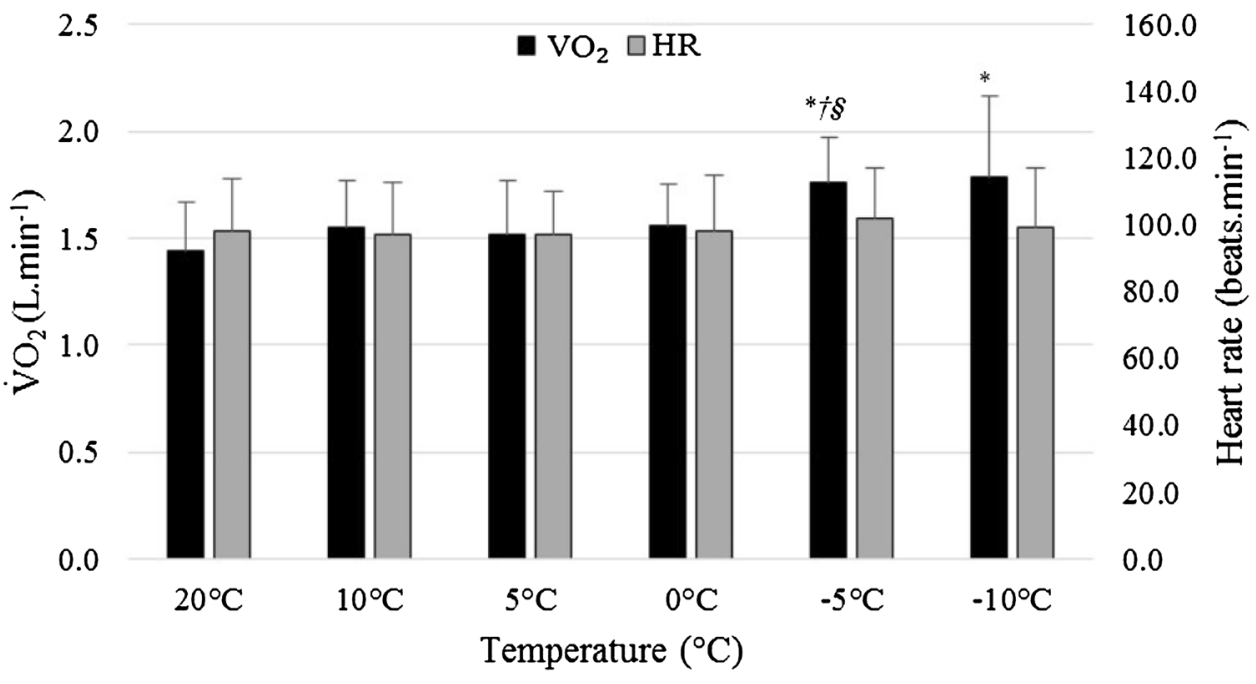

from 0 to $10 \%$ gradient were similar across all temperatures $\left(p=0.814, \eta_{\mathrm{p}}^{2}=0.043\right)$.

\section{Differential effects}

Further analysis comparing unloaded 1 and loaded conditions showed a significant interaction between load and gradient ( $p=0.013, \eta_{\mathrm{p}}{ }^{2}=0.475$, Fig. 2a). Figure 2a shows that gradient had a greater impact than backpack load on $\mathrm{VO}_{2}$. The effect of load was greater at $10 \%$ gradient (mean difference $=0.37 \mathrm{~L} \cdot \mathrm{min}^{-1}$ ) than when compared to the change at $0 \%$ (mean difference $=0.24 \mathrm{~L} \cdot \mathrm{min}^{-1}$ ). In addition, the effect of gradient was greater when participants were loaded than when unloaded (mean difference $=0.85$ and $0.72 \mathrm{~L} \cdot \mathrm{min}^{-1}$, respectively). This interaction can be categorised as a synergistic increase (hyper-additive, Fig. 1b).

Figure 3 shows the interactions between the temperature and the three load conditions. The pattern of response was similar between unloaded 1 and loaded walking. This was confirmed by no significant two-way or threeway interactions $\left(p \geq 0.127, \eta_{\mathrm{p}}{ }^{2} \leq 0.168\right)$. There was a significant interaction between temperature and load $\left(p=0.011, \eta_{\mathrm{p}}^{2}=0.268\right)$ when comparing walking loaded with unloaded 2. At warmer temperatures, as expected, loaded and unloaded 2 exercise bouts produced different $\mathrm{VO}_{2}$ values, due to the effect of load. However, at colder ambient temperatures $\left(-5^{\circ} \mathrm{C}\right.$ or $\left.-10^{\circ} \mathrm{C}\right), \mathrm{VO}_{2}$ values were similar for the second unloaded exercise and when carrying the $18.2 \mathrm{~kg}$ load. Figure $4 \mathrm{a}$ shows that a combination of decreasing temperature and increasing load produced an antagonistic (hypo-additive) interaction, including an increase of $47.3 \pm 36.8 \%$ from 20 to $-10{ }^{\circ} \mathrm{C}$ for unloaded 2 , an increase of $21.2 \pm 5.8 \%$ when backpack load was added and a combined increase of $53.5 \pm 29.9 \%$ in $\mathrm{VO}_{2}$ at $-10^{\circ} \mathrm{C}$ for loaded compared to unloaded 2 at $20^{\circ} \mathrm{C}$. There was also a significant interaction between temperature and load $\left(p<0.001, \eta_{\mathrm{p}}{ }^{2}=0.392\right)$ when comparing unloaded 1 with unloaded 2 walking. The interaction is indicated by no differences at higher temperatures in contrast to the colder ambient temperatures $\left(-5\right.$ and $\left.-10^{\circ} \mathrm{C}\right)$ which produced higher $\mathrm{VO}_{2}$ values that were consistent with the loaded condition. At $-10^{\circ} \mathrm{C}$, the mean difference between the two unloaded conditions was $0.29 \pm 0.36 \mathrm{~L} \cdot \mathrm{min}^{-1} \mathrm{com}-$ pared to $-0.01 \pm 0.09 \mathrm{~L} \cdot \mathrm{min}^{-1}$ at $20^{\circ} \mathrm{C}$. Figure $4 \mathrm{~b}$ shows that a combination of low temperature and prolonged exposure (unloaded 2) produced a hyper-additive interaction. This comprised of an increase of $23.3 \pm 18.1 \%$ from 20 to $-10^{\circ} \mathrm{C}$ for unloaded 1 , a $0.5 \pm 7.4 \%$ decrease from unloaded 1 to unloaded 2 at $20^{\circ} \mathrm{C}$, with an increase of $46.5 \pm 37.4 \%$ in $\mathrm{VO}_{2}$ at $-10^{\circ} \mathrm{C}$ for unloaded 2 compared to unloaded 1 at $20^{\circ} \mathrm{C}\left(\right.$ mean difference $\left.=0.59 \mathrm{~L} \cdot \mathrm{min}^{-1}\right)$.

\section{Heart rate}

HR values for some participants contained outliers, therefore, they were removed from the analysis, so $n=8$. As for $\mathrm{VO}_{2}, \mathrm{HR}$ varied significantly across the three loaded conditions $\left(p<0.001, \eta_{\mathrm{p}}{ }^{2}=0.800\right)$ and was significantly greater for loaded walking compared to unloaded walking $(p \leq 0.001)$. HR was also significantly greater when walking uphill compared to level ground $(p<0.001$, $\left.\eta_{\mathrm{p}}{ }^{2}=0.925\right)$. In contrast to $\mathrm{VO}_{2}$, ambient temperature did not significantly affect $\mathrm{HR}$ responses $(p=0.377$, $\eta_{\mathrm{p}}{ }^{2}=0.136$, Fig. 1). In addition, when comparing unloaded 1 and unloaded 2, there were no significant differences in heart rate with temperature $\left(p=0.366, \eta_{\mathrm{p}}^{2}=0.138\right)$. Figure 5 shows that across all conditions, the HR increased with $\mathrm{VO}_{2}$, as would be expected. However, within each of 
Fig. 2 Mean $\pm \mathrm{SD} \mathrm{VO}_{2}$

$\left(\mathrm{L} \cdot \mathrm{min}^{-1}\right.$ ) responses for Unloaded 1 and Loaded at 0 and $10 \%$ gradient averaged across all ambient temperatures. Asterisk denotes a significant difference to $0 \%$ responses for the same load, dagger denotes a significant difference to unloaded responses for the same gradient, and integral symbol denotes an interaction effect for gradient $\times$ load. $\mathbf{b}$ Interaction showing mean percentage change in $\mathrm{VO}_{2}\left(\mathrm{~L} \cdot \mathrm{min}^{-1}\right)$ from $0 \%$ gradient, unloaded 1 , averaged across all ambient temperatures a

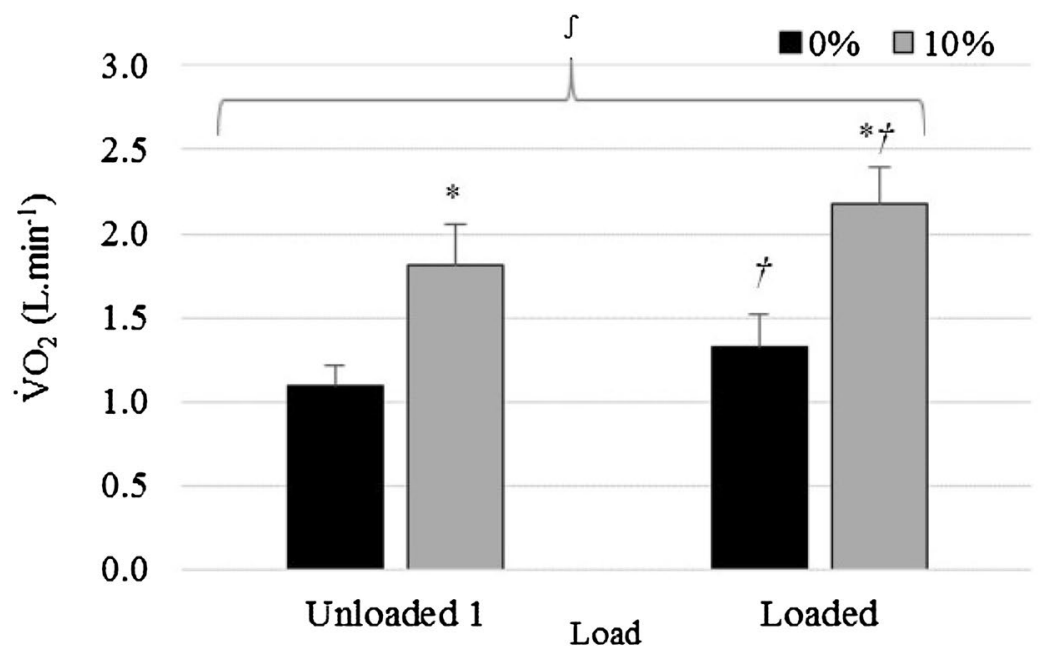

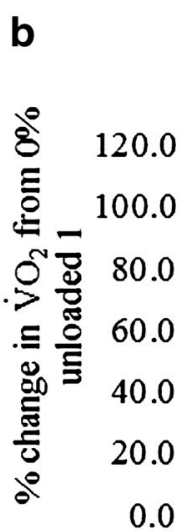

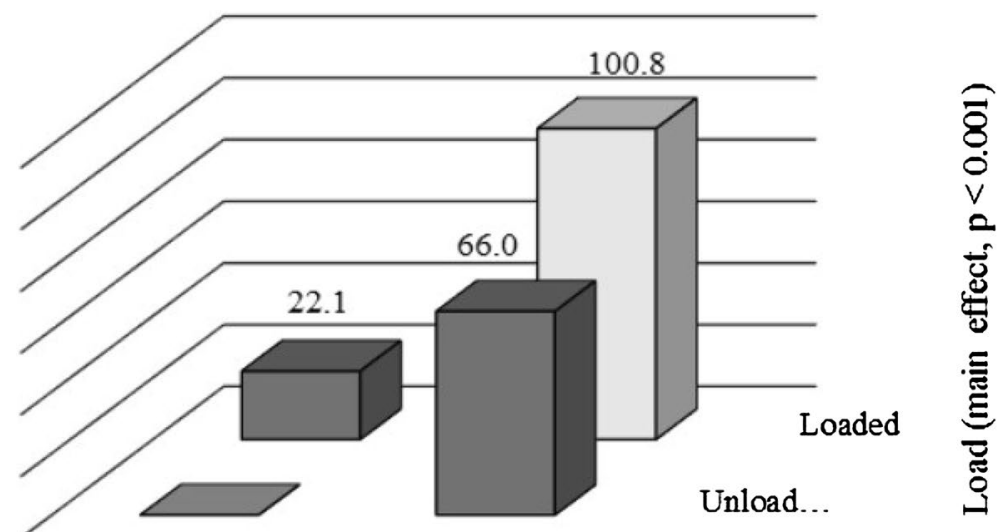

$0 \%$

$10 \%$

Gradient $(\%$, main effect, $p<0.001)$
Fig. 3 Mean $\pm \mathrm{SD} \mathrm{VO}_{2}$ $\left(\mathrm{L} \cdot \mathrm{min}^{-1}\right.$ ) response for Unloaded 1, Loaded and Unloaded 2 phases for all ambient temperatures, averaged across all gradients

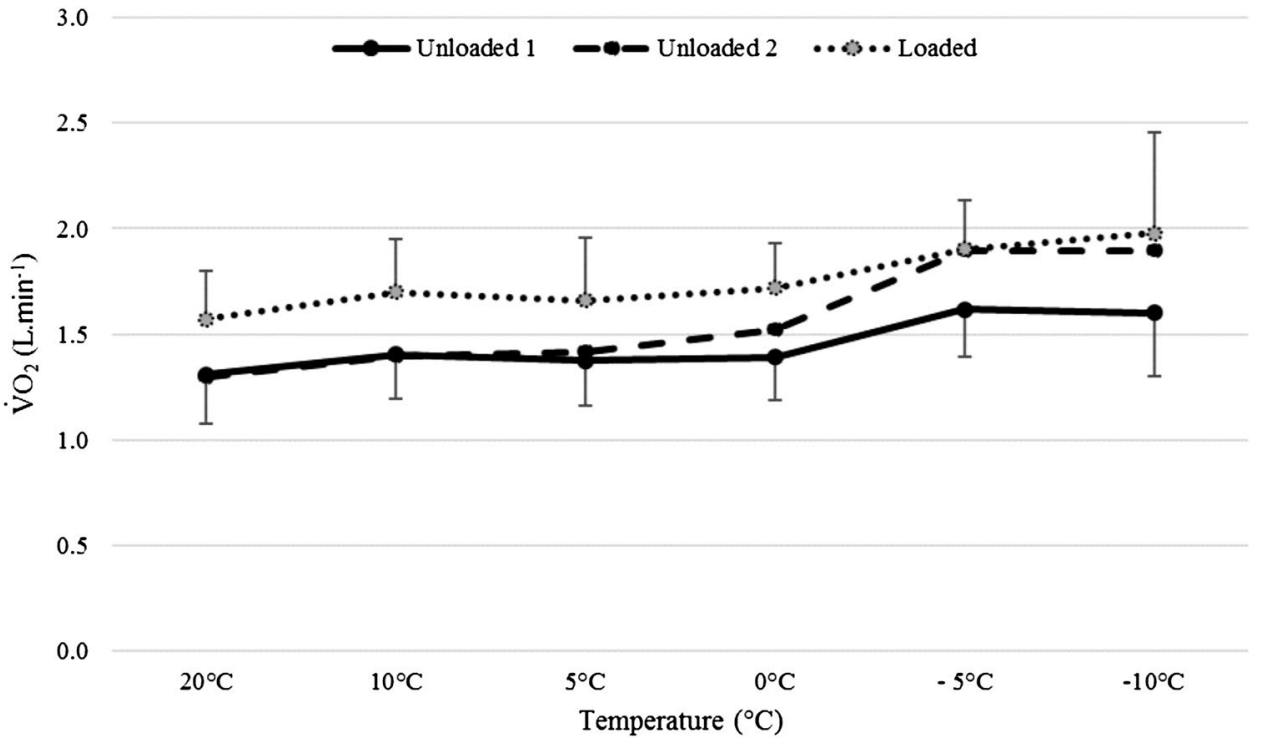


Fig. 4 Interactions showing mean percentage change in $\mathrm{VO}_{2}\left(\mathrm{~L} \cdot \mathrm{min}^{-1}\right)$ from $20^{\circ} \mathrm{C}$, unloaded 2 (a) and from $20^{\circ} \mathrm{C}$ unloaded 1 (b) averaged across all gradients

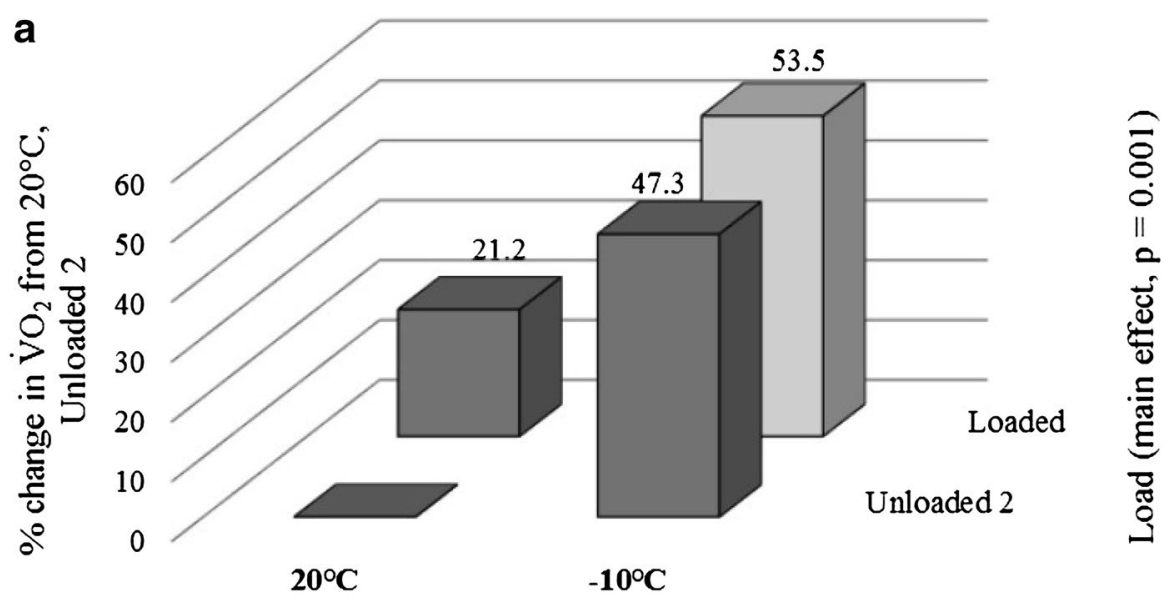

Temperature $\left({ }^{\circ} \mathrm{C}\right.$, main effect, $\left.\mathrm{p}<0.001\right)$

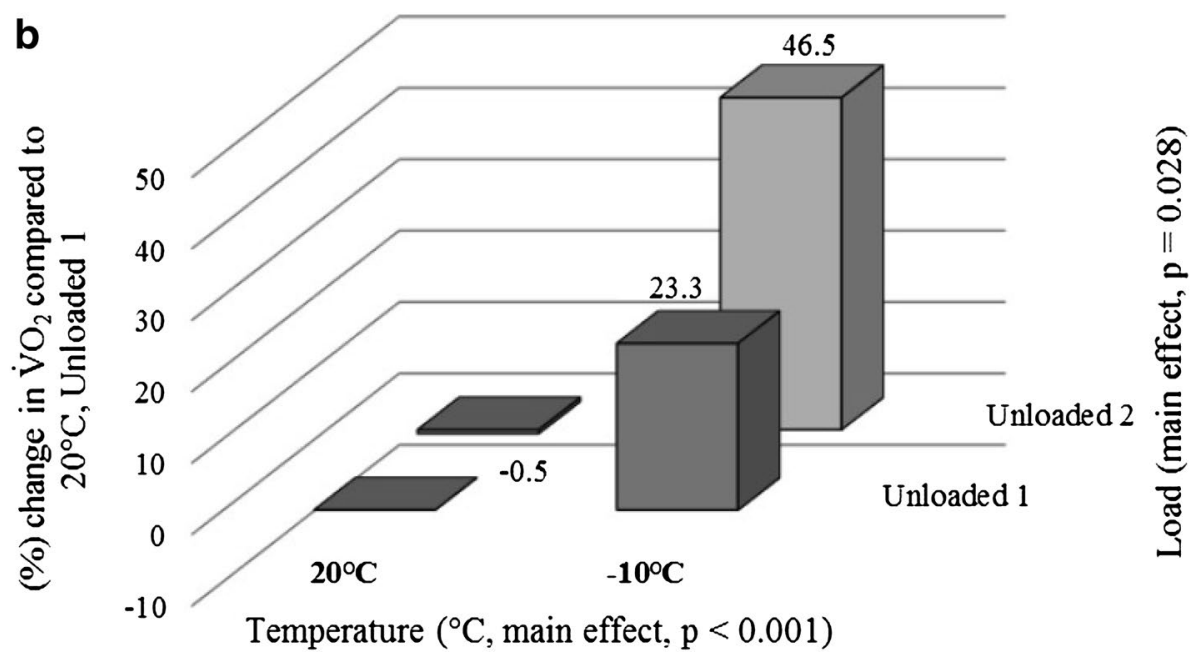

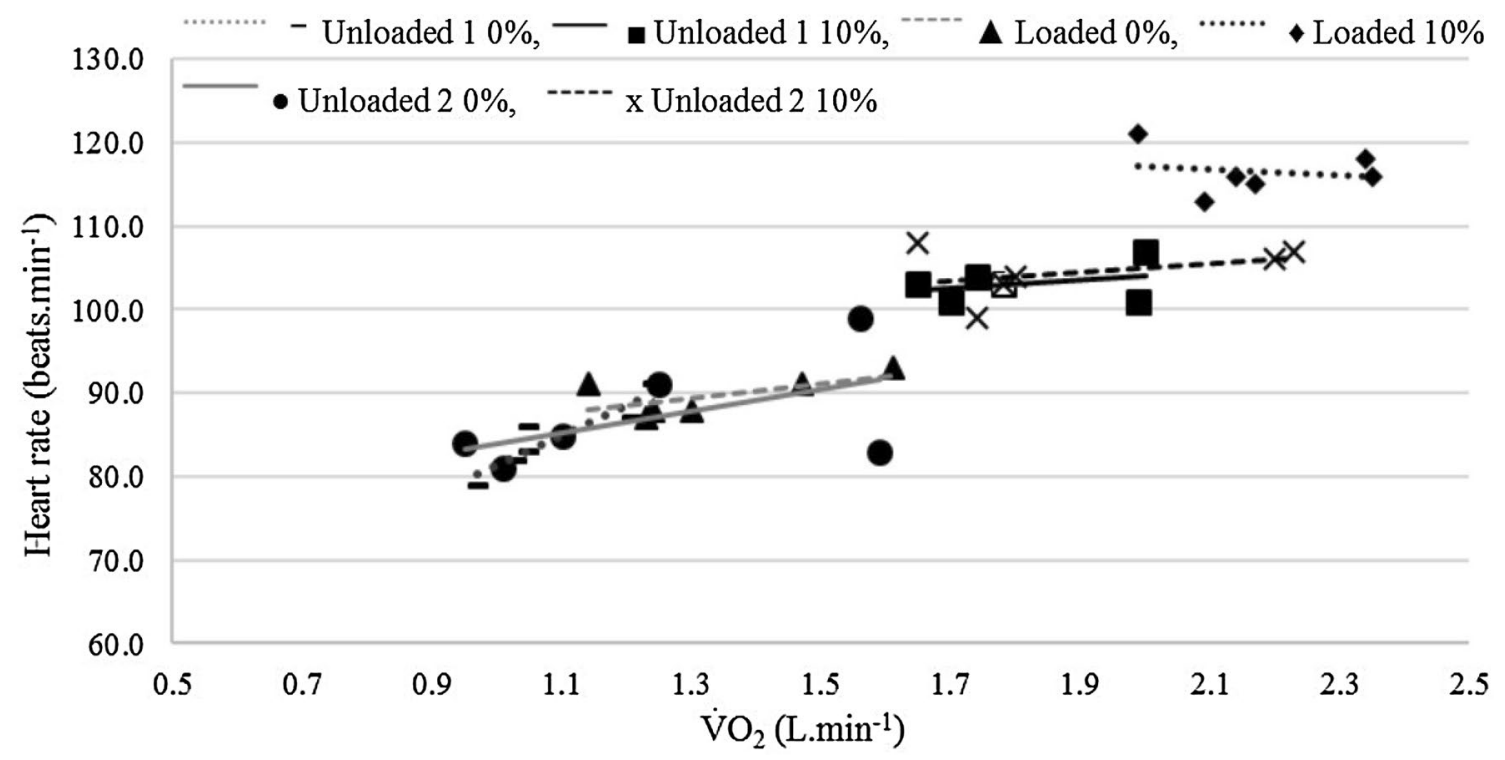

Fig. 5 Correlation between absolute $\mathrm{VO}_{2}\left(\mathrm{~L} \cdot \mathrm{min}^{-1}\right)$ and $\mathrm{HR}$ values (beats $\cdot \mathrm{min}^{-1}$ ) for each phase with all temperatures included 
the conditions across the five different temperatures HR did not increase with $\mathrm{VO}_{2}$ in a systematic or consistent way as indicated by the line of best fit for each load and gradient condition in Fig. 5. For example, unloaded $10 \%$ shows a strong relationship between $\mathrm{VO}_{2}$ and $\mathrm{HR}(r=0.91)$. In contrast, unloaded 2 at $10 \%$ shows a much weaker relationship $(r=0.37)$, accounting for only $14 \%$ of the variance. This is because the $\mathrm{HR}$ response at -5 and $-10^{\circ} \mathrm{C}$ is no different to the responses for higher temperatures, yet the $\mathrm{VO}_{2}$ increased by $1.0 \mathrm{~L} \cdot \mathrm{min}^{-1}$ from the warmest to the coldest temperature.

\section{Peripheral and core temperatures}

Skin temperature was recorded for 10 out of the 11 participants. Figure 6 shows that mean skin temperature (MST) was significantly reduced with decreasing temperature $\left(p<0.001, \eta_{\mathrm{p}}{ }^{2}=0.931\right)$. Similarly, there was a significant effect of time with baseline readings being significantly higher than those towards the end of exposure despite participants exercising $\left(p<0.001, \eta_{\mathrm{p}}{ }^{2}=0.966\right)$. Figure 6 also demonstrates an interaction effect for temperature and time $\left(p<0.001, \eta_{\mathrm{p}}^{2}=0.748\right)$ showing a greater reduction in MST over time at colder ambient temperatures.

Core temperature decreased slowly throughout the $-10^{\circ} \mathrm{C}$ exposure by $0.75 \pm 0.6^{\circ} \mathrm{C}$ from a baseline value of $37.41 \pm 0.45^{\circ} \mathrm{C}$.

\section{Kinematics}

\section{Effect of gradient}

Walking uphill caused SL to be significantly greater than for level walking; $1.25 \pm 0.08 \mathrm{~m}$ for $0 \%$ and $1.29 \pm 0.10 \mathrm{~m}$ for $10 \%$ grade, demonstrated by a main effect of gradient $\left(p=0.008, \eta_{\mathrm{p}}^{2}=0.564\right)$. Similarly, an increase in gradient also elicited a significantly greater trunk forward lean $\left(\mathrm{TFL}, \sim 4.43^{\circ}\right)$ in all three gait phases $\left(p<0.001, \eta_{\mathrm{p}}{ }^{2} \geq\right.$ $0.941)$.

\section{Effect of load}

There was no main effect of load across the three load conditions on SL $\left(p=0.871, \eta_{\mathrm{p}}{ }^{2}=0.015\right)$, however, backpack load caused TFL in all gait phases to be significantly greater regardless of temperature $\left(p<0.001, \eta_{\mathrm{p}}{ }^{2}=0.780\right)$.

\section{Effect of temperature}

As ambient temperature decreased, SL significantly decreased $\left(p=0.005, \quad \eta_{\mathrm{p}}^{2}=0.300\right)$. Combining gradients and loads, SL at $20^{\circ} \mathrm{C}$ measured $1.29 \pm 0.10 \mathrm{~m}$ compared to $1.25 \pm 0.10 \mathrm{~m}$ at $-10^{\circ} \mathrm{C}$. Post-hoc tests revealed a significant difference between $5^{\circ} \mathrm{C}$ and $-5^{\circ} \mathrm{C}$ (mean difference $=-0.024 \mathrm{~m}, p=0.041$ ). There were no significant interactions between temperature, with load or

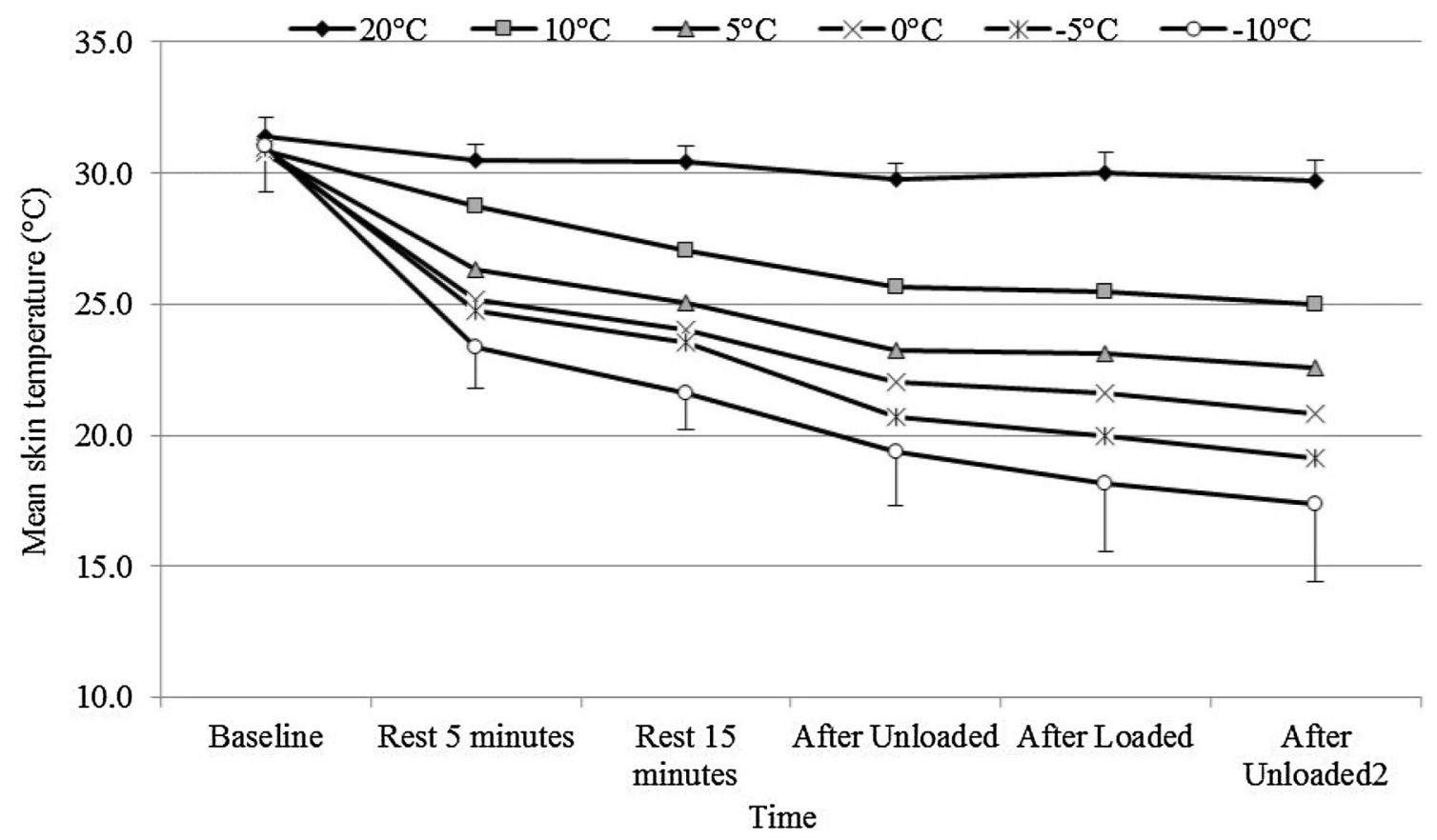

Fig. 6 Mean \pm SD Mean skin temperature (MST, ${ }^{\circ} \mathrm{C}$ ) across the whole protocol for all temperatures 
gradient $(p \geq 0.110)$ or a three-way interaction $(p=0.274$, $\left.\eta_{\mathrm{p}}^{2}=0.122\right)$.

There were mixed results regarding temperature and TFL. Mid-stance showed no significant differences $\left(p=0.115, \eta_{\mathrm{p}}{ }^{2}=0.174\right)$ between the different ambient temperatures. In contrast, measurements for left heel strike showed that participants leaned further forward at colder temperatures (a significant main effect for temperature: $\left.p=0.029, \eta_{\mathrm{p}}{ }^{2}=0.235\right)$. Left toe-off showed a trend for greater TFL at colder temperatures $\left(p=0.054, \eta_{\mathrm{p}}{ }^{2}=0.209\right)$. Table 2 shows the main effect of temperature during left heel strike. There were no reported interactions for temperature with load or gradient with regard to TFL $(p \geq 0.299$, $\left.\eta_{\mathrm{p}}^{2} \leq 0.111\right)$.

\section{Interaction effects}

A significant interaction for SL between load and gradient was reported when comparing unloaded 1 and loaded conditions $\left(p=0.001, \eta_{\mathrm{p}}{ }^{2}=0.656\right)$. The effect of gradient on SL was greater than that of backpack load. When a combination of both load and gradient occurred, SL was increased by $3.7 \pm 4.3 \%$ above unloaded $0 \%$ walking. This was classified by Lloyd and Havenith (2016) as a hypoadditive (antagonistic) interaction, as gradient and loaded separately caused a $4.9 \pm 3.7 \%$ and $1.4 \pm 2.1 \%$ increase in SL, respectively. In contrast to $\mathrm{VO}_{2}$, when comparing the two unloaded conditions, prolonged exposure to lower ambient air temperatures had no effect on SL, as demonstrated by a non-significant interaction between temperature and load $\left(p=0.232, \eta_{\mathrm{p}}{ }^{2}=0.137\right)$.

At left toe-off, when comparing unloaded 1 and loaded conditions, there was an interaction effect between load and gradient for TFL, as shown in Fig. 7a $(p=0.037$, $\left.\eta_{\mathrm{p}}{ }^{2}=0.367\right)$. Figure $7 \mathrm{a}$ shows that backpack load had a greater effect on TFL than gradient. Figure $7 \mathrm{~b}$ shows that the two conditions together (load and 10\% incline combined) caused an additive relative effect (percentage

Table 2 Mean \pm SD Trunk forward lean $\left({ }^{\circ}\right)$ during left heel strike for all environmental temperatures averaged across all gradients and loads

\begin{tabular}{ll}
\hline Temperature $\left({ }^{\circ} \mathrm{C}\right)$ & TFL $\left({ }^{\circ}\right)$ \\
\hline 20 & $94.7 \pm 3.4^{*}$ \\
10 & $94.9 \pm 2.4$ \\
5 & $94.5 \pm 3.5$ \\
0 & $94.6 \pm 3.5^{*}$ \\
-5 & $95.2 \pm 2.4$ \\
-10 & $96.8 \pm 2.8$ \\
\hline
\end{tabular}

*Denotes a significant difference to $-10^{\circ} \mathrm{C}(p<0.05)$ increase, $7.2 \pm 4.0 \%$ increase for load, $5.9 \pm 1.7 \%$ increase for gradient, and $12.1 \pm 4.7 \%$ increase when combined).

\section{Discussion}

\section{Oxygen consumption}

The first novel finding in this study was that the effect of load was not significantly different between the different ambient temperatures. Walking with an $18.2 \mathrm{~kg}$ backpack at $-10^{\circ} \mathrm{C}$ elicited a similar absolute $\Delta \mathrm{VO}_{2}$ response to that at $20^{\circ} \mathrm{C}$ for both level and uphill walking.

The increases in $\mathrm{VO}_{2}$ seen during both the two unloaded and loaded exercise bouts at sub-zero temperatures compared to thermo-neutral and cool temperatures indicate that the submaximal oxygen consumption was higher in the cold environment. The findings from this study add to the body of literature to show at what temperatures $\mathrm{VO}_{2}$ is significantly affected. Our results support the findings of Sandsund et al. (1998) who found that during cold exposure $\left(-15^{\circ} \mathrm{C}\right), \mathrm{VO}_{2}$ was significantly higher (by $10.8 \%$ ) during submaximal running exercise intensities. This is a smaller percentage increase compared to the present findings as the current study found on average, $\mathrm{VO}_{2}$ was $20.5 \%$ higher at $-10^{\circ} \mathrm{C}$ compared to $20^{\circ} \mathrm{C}$. Differences in the effect on $\mathrm{VO}_{2}$ could be due to the higher exercise intensities employed, as Sandsund et al. (1998) averaged $\mathrm{VO}_{2}$ over running intensities of $50-95 \% \mathrm{VO}_{2 \max }$. Studies have shown that as exercise intensity increases, the effect of the cold becomes lessened due to an increase in heat production from the exercise (Pugh 1967). The results from the present study are also in agreement with findings by Oksa et al. (2004), who showed that at a workload of $25 \% \mathrm{VO}_{2 \max }, \mathrm{VO}_{2}$ was significantly higher during cold exposure $\left(-15^{\circ} \mathrm{C}\right)$ than at $20^{\circ} \mathrm{C}$ $(p<0.05)$. Similarly, when exercising at $50 \% \mathrm{VO}_{2 \max }$, in 0 and $-15^{\circ} \mathrm{C}$ conditions, $\mathrm{VO}_{2}$ significantly increased almost linearly when compared to results at $20^{\circ} \mathrm{C}$. Whilst $\mathrm{VO}_{2}$ was greater in the cold, reflecting findings by Oksa et al. (2004), the increase in $\mathrm{VO}_{2}$ was not linear. Results from the present study did differ to the previous findings as Oksa et al. (2004) reported that heart rate results mirrored those of $\mathrm{VO}_{2}$ at both intensities, whereas our findings showed that heart rate did not change in proportion to changes in $\mathrm{VO}_{2}$ with temperature. The participants in the study by Oksa et al. (2004) wore layered clothing weighing up to $4.9 \mathrm{~kg}$ at $-15^{\circ} \mathrm{C}$. It is unclear how much of an effect this additional weight had on $\mathrm{VO}_{2}$, but it would be expected to increase it in absolute terms, although not relative to total mass, but this could explain the increased heart rate response found by Oksa et al. (2004).

The reasons for a higher $\mathrm{VO}_{2}$ response during cold exposure are likely due to reduced mechanical efficiency 
Fig. 7 a Mean \pm SD TFL $\left({ }^{\circ}\right)$ during toe-off for Unloaded 1 and Loaded at 0 and $10 \%$ gradient averaged across all ambient temperature. Asterisk denotes a significant difference to $0 \%$ responses for the same load, and dagger denotes a significant difference to unloaded responses for the same gradient. Integral symbol denotes an interaction effect for gradient $\times$ load. b Interaction showing mean percentage change in TFL $\left(^{\circ}\right)$ from $0 \%$ gradient, unloaded 1 , averaged across all ambient temperatures

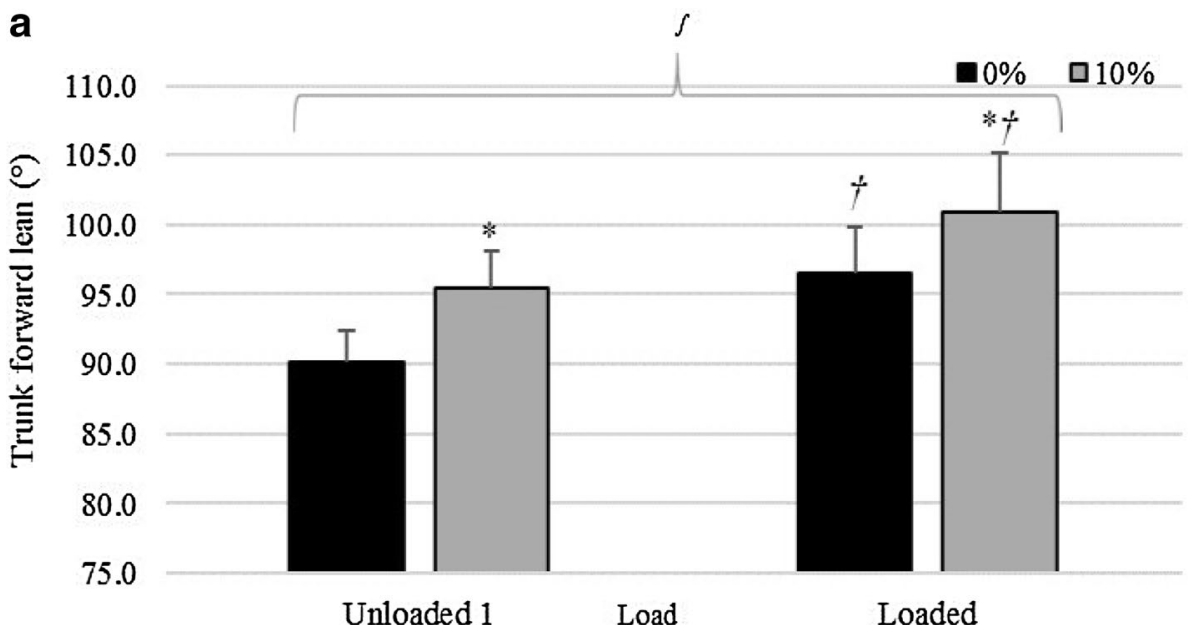

b

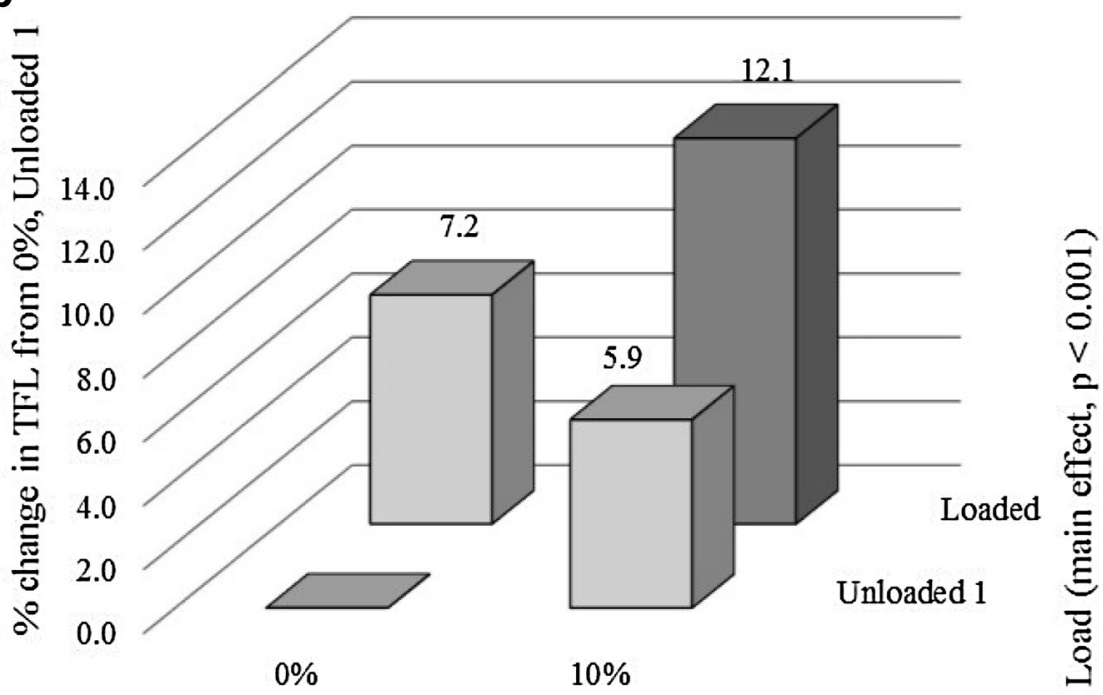

Gradient ( $\%$, main effect, $\mathrm{p}<0.001)$ ) and thus increased co-activation of muscle pairs. Muscle strength has been previously demonstrated to be reduced during cold exposure and has been attributed to a number of factors including slowed calcium uptake, ATP utilisation and a reduction in cross-bridge force kinetics (Oksa et al. 2004). Wakabayashi et al. (2015) reported that during exercise in the cold, EMG amplitude has been shown to be increased. This evidence suggests that to maintain the same walking speed of $4 \mathrm{~km} \cdot \mathrm{h}^{-1}$, participants may have recruited more muscles fibres as the more superficial muscle fibres become weakened by the cold (Oksa 2002; Castellani and Tipton 2016). If more motor units are employed to meet the exercise demands this will increase $\mathrm{VO}_{2}$ as reflected in the present study by greater $\mathrm{VO}_{2}$ values at -10 and $-5{ }^{\circ} \mathrm{C}$.

Another likely cause for elevated $\mathrm{VO}_{2}$ associated with cold exposure is shivering in an attempt to maintain core temperature (Doubt 1991). The unparalleled activation of skeletal muscle fibres generates heat, increasing the requirement for carbohydrate oxidation which results in quicker glycogen depletion. The exercise intensity when walking with a load, however, was above the estimated $1.5 \mathrm{~L} \cdot \mathrm{min}^{-1}$ threshold for the shivering response; therefore, it is unlikely that this was the only explanation (Sandsund et al. 1998). In the present study and in agreement with Ito et al. (2013) and Castellani and Tipton (2016), the absence of overt shivering observed during exercise in some conditions combined with small change in deep body temperature and increased $\mathrm{VO}_{2}$ could be attributed to the generation of heat through non-shivering thermogenesis (NST). BAT releases norepinephrine which causes the breakdown of triglycerides, releasing fatty acids which in turn activates an uncoupling protein (UCP1) (Nedergaard et al. 2011). Substrate oxidation is then uncoupled or dissociated from the production of ATP, leading to an increased heat production (Cannon and Nedergaard 2004). 
Calorigenic hormones increase the oxygen consumption in most cells, increasing the basal metabolic rate, reflected as elevated $\mathrm{VO}_{2}$ during exposure to the cold (Ito et al. 2013). The contribution of NST to the whole body metabolic response is not fully understood, and Ouellet et al. (2012) reported a 1.8-fold increase in energy expenditure in participants after cold exposure. Total energy expenditure increased from $125.6 \mathrm{~W}\left(0.36 \mathrm{~L} \cdot \mathrm{min}^{-1}\right)$ to $222.6 \mathrm{~W}$ $\left(0.64 \mathrm{~L} \cdot \mathrm{min}^{-1}\right)$, causing an average increase in $\mathrm{VO}_{2}$ of $\sim 0.3 \mathrm{~L} \cdot \mathrm{min}^{-1}$. This was during an experiment conducted at a water temperature of $18^{\circ} \mathrm{C}$, and the contribution to energy expenditure during cold air temperatures should be considered in future research. Researchers, however, have concluded that BAT undoubtedly contributes to a coldinduced increase in energy expenditure and both NST and shivering contribute to the whole body metabolic response (Ouellet et al. 2012). The two mechanisms, thermogenesis and neuromuscular changes, do not work in isolation. Increased shivering and NST, particularly in the antagonist muscle, will also reduce mechanical efficiency. This occurs principally due to the increased requirement of the agonist muscle to produce a larger force/power output and thereby increased oxygen consumption to compensate for a higher antagonist/ joint resistance when the muscle becomes cold (Oksa 2002). The colder the ambient temperature, the greater the decrease in superficial muscle temperature meaning a greater reduction in muscle strength and blood flow, at least to superficial areas (Oksa et al. 2004). Vasoconstriction reduces blood flow to the muscle, and thus, oxygen delivery to working muscles may be reduced, leading to an earlier switch to anaerobic metabolism (Sandsund et al. 1998; Ito et al. 2013; Castellani and Tipton 2016). This combined with an increase in carbohydrate utilisation due to shivering would increase the accumulation of lactic acid, impairing performance and inducing fatigue (Jett et al. 2006). Muscle temperature was not measured in the present study; therefore, there is need for further work to evaluate this response.

The second novel finding from this investigation was the effect of prolonged exposure in the cold on $\mathrm{VO}_{2}$ as highlighted though the interaction between temperature and load. At sub-zero temperatures, the second bout of unloaded exercise elicited a significantly higher $\mathrm{VO}_{2}$ response to the first unloaded bout which was not observed when exercising at temperatures of $0{ }^{\circ} \mathrm{C}$ and above. This finding can be attributed to both mechanisms described previously, as the greater the time spent in the cold, the lower the core and skin temperature. This would elicit greater responses from defence mechanisms, such as shivering and additional recruitment of motor units to sustain workload and prevent hypothermia. This finding would support an increase in the $\% \mathrm{VO}_{2 \max }$ that individuals would be working at when exercising in conditions of cold exposure which would induce faster fatigue and could lead to early termination of load carriage exercise. It could be suggested that the $\mathrm{VO}_{2}$ values shown when loaded at sub-zero temperatures could be affected by cold exposure too, as this bout of exercise occurs after unloaded 1 and the body would have had time to cool. However, the data in the present study show that this is very unlikely due to the effect of loading being stable across the temperatures, as shown in Fig. 3.

Gradient had a greater impact on $\mathrm{VO}_{2}$ than backpack load did. This can be attributed to the vertical work done during exercise on a gradient causing a greater increase in metabolism than extra load alone, as the body has to work to produce both horizontal movement and movement against gravity (Santee et al. 2001).

\section{Heart rate}

There is no universally accepted response of HR to cold exposure. Within the literature, HR during submaximal exercise has been shown to decrease (e.g., Kruk et al. 1991; Spitz et al. 2014), increase (Oksa et al. 2004), or remain unchanged (e.g., Patton and Vogel 1984). Results from this study support the latter, as decreasing ambient temperature had no effect on HR responses. Vasoconstriction is likely to have occurred due to significant reductions in MST shown in the lower ambient temperatures; however, this had no effect on HR. It could be suggested that exposure time in the present study was not sufficient for the cold to influence HR. However, the duration of the protocol in the present study was 50-60 min, depending on the length of rest periods. Spitz et al. (2014) employed protocols of a similar duration ( $\sim 60 \mathrm{~min})$, and yet, they reported significant differences in HR responses. In addition, those authors did not use temperatures as cold as those in the present study. Consequently, protocol duration is unlikely to have been the sole reason for no change in HR. A difference in exercise intensity, exercise modality, or body composition could have influenced results.

\section{Biomechanical factors}

Load reduces SL when walking on the horizontal and is regarded advantageous due to the decrease in stress on the bones of the foot (Knapik et al. 1996; Lloyd and Cooke 2011). However, most of the literature has reported only small decreases, and in the present study, no differences were found. In agreement with $\mathrm{VO}_{2}$ data, gradient caused a greater change in SL than backpack load. To counteract the resistance caused by gravity when walking uphill, individuals seek to increase momentum in their lower limbs which is achieved through increased SL (Leroux et al. 2002). TFL, however, displayed a different pattern of response with backpack load having a greater impact than gradient. 
This can be attributed to load affecting the CoM of an individual to a greater extent than gradient, causing participants to alter their posture to maintain stability (Singh and Koh 2009; Simpson et al. 2011).

Finally, the present study is able to add to the very limited evidence on changes in gait characteristics with ambient temperature. We found a reduction in SL to maintain the constant walking speed. Changes in spatiotemporal parameters could be attributed to the decrease in muscle tendon elasticity that occurs with decreasing temperature. Folland et al. (2006) proposed that stiffer tendons could reduce the amount of stored energy involved in the eccentric loading phase of running/walking which would reduce the net impulse distributed to the runner, decreasing stride length. For the runner or walker to sustain their speed, the solution would be to increase SF. Our results confirm findings by Folland et al. (2006) who showed that their cold trial caused significant increases in SF and concurrent decreases in SL when compared with gait parameters in thermo-neutral and hot conditions. They reported reductions of $0.04 \mathrm{~m}$ in SL in line with the reductions reported in the present study. Their cold exposure however was a precooling exposure in water, and to date, there are no published investigations in cold air exposure on stride parameters, and this is the first study to report such findings.

A different mechanical response was demonstrated when walking uphill, which increased SL. This is in agreement with the few studies investigating stride parameters on varying gradients (Kawamura et al. 1991; Leroux et al. 2002; Fellin et al. 2016) yet in contrast to findings by McIntosh et al. (2006) who reported the opposite, with a decrease in $\mathrm{SL}$ as gradient increased from $-10^{\circ}$ to $0^{\circ}$. McIntosh et al. (2006) suggested the difference in their findings to other studies could be attributed to the length of the short walkway used to collect data $(7 \mathrm{~m})$ preventing participants from finding their normal gait pattern.

While temperature and gradient produced different responses in SL, both conditions produced significant increases in TFL. It has been suggested by Leroux et al. (2002) that as gradient increases, the momentum of the lower legs must also increase to overcome gravity, resulting in increases in SL. In this case, increased TFL is beneficial to the development of momentum in the lower limbs as moving body weight forward of the hip aids flexion of the hip. However, increased TFL can also be an adaptive response to decreased SL, particularly if muscle function is compromised ( $\mathrm{Li}$ et al. 2013) as suggested in cold exposure conditions (Folland et al. 2006). Increasing TFL has the effect of moving the ground reaction force line anterior to the knee thereby aiding stability in the knee extensorplantar flexion couple mechanism during limb loading (Kirtley 2006). The significant increases in TFL observed in the current study at left heel strike and left toe-off during cold exposure correspond with limb loading events in the gait cycle.

Previous studies reporting the effect of load on stride parameters are somewhat equivocal. Some authors have reported increases in SL with increasing load (e.g. Lloyd and Cooke 2011), whilst others report decreases in SL (Knapik et al. 1996; Harman et al. 2000). Knapik et al. (1996) proposed that a reduction in SL is advantageous due to the decrease in stress on the bones of the foot. The present findings associated with SL and load were similar to other studies, where no significant changes for SL were observed with increasing load (e.g., Singh and Koh 2009).

Phillips et al. (2016b) reported disproportional increases in $\mathrm{VO}_{2}$ with systematic increases in gradient when participants were walking at a constant speed. It was suggested that biomechanical changes, such as increased forward lean, were primarily responsible for these responses as TFL increased the muscle activity in the abdominals and lower back, which in turn required a greater $\mathrm{VO}_{2}$ (Phillips et al. 2016b). Biomechanical variables were not measured in the study by Phillips et al. (2016b); thus, the authors suggestions were purely speculative. The results from the present study show that although the oxygen cost of walking uphill with a load was disproportionately greater, the suggestion that this could be attributed to TFL alone can be refuted. The present study found that the change in TFL from the unloaded to loaded condition was greater during level walking than at a $10 \%$ gradient, whereas the effect of gradient upon $\mathrm{VO}_{2}$, was greater when unloaded compared with loaded walking. Biomechanical changes could indeed be responsible for the disproportional increases in $\mathrm{VO}_{2}$; however, the mechanism would appear to be more complex than simply increased TFL alone.

\section{Practical application}

Understanding how load carriage affects physiological responses can provide information on how best to prepare for situations, where load carriage is a feature of the exercise challenge, such as in trekking or mountaineering. In terms of cold exposure, being inadequately dressed in cold environments would induce fatigue due to an increased $\mathrm{VO}_{2}$ response and a probable reduction in muscle strength with decreasing temperature for the same exercise intensity. Therefore, ensuring that skin temperature does not significantly decrease would be a major consideration when exercising in cold environments. When visiting cold climates, it is also worth bearing in mind the possibility of the extra energy expenditure required to undertake the same exercise challenge if clothing does not compensate for the effects of cold exposure. This has implications for training and fitness. Individuals should as much as possible employ task specificity to elicit the training response; therefore, they 
should adjust their training regimes to account for the extra energy requirement associated with exercising in cold ambient temperatures and/or with a load. Due to colder temperatures eliciting a greater $\mathrm{VO}_{2}$ response, individuals would be recommended to train at a higher intensity. At $-10^{\circ} \mathrm{C}$, walking with a load required an extra average oxygen consumption of $\sim 0.41 \mathrm{~L} \cdot \mathrm{min}^{-1}$ when compared to loaded walking at $20^{\circ} \mathrm{C}$ and an extra $\sim 0.67 \mathrm{~L} \cdot \mathrm{min}^{-1}$ when compared to unloaded walking at $20^{\circ} \mathrm{C}$.

\section{Limitations}

Core temperature pills were only given for trials at $-10^{\circ} \mathrm{C}$ as a safety measure to ensure participants did become hypothermic. Ideally core temperature pills would have been used throughout; however, due to logistical reasons, this was not possible. For future work, measuring core temperature in all trials to see the effect of the protocol for a range of different ambient temperatures should be considered. In addition, no $\mathrm{VO}_{2 \max }$ data were collected for participants. The effect of cold exposure on $\mathrm{VO}_{2 \max }$ is well reported, but findings are inconsistent. Nonetheless, the majority of literature suggests that $\mathrm{VO}_{2 \max }$ does not change with a decrease in ambient temperature (Sandsund et al. 2012); therefore, as the effect of load did not change across the different ambient temperatures, it could be hypothesised that $\% \mathrm{VO}_{2 \max }$ would be similar also. The same backpack was used for all participants; future work may consider using one model with various sizes, so that the pack can be custom fitted to each participant. The brief exercise bouts were also a limitation, but due to technical issues of freezing sample lines during cold exposure, exercise periods were kept to $14 \mathrm{~min}$. As mentioned previously, Lloyd and Cooke (2000) and the current data showed that this time period was sufficient in establishing steady state.

\section{Conclusion}

The evidence leads to a rejection of the first hypothesis as the results of this investigation show that ambient temperature had no significant effect on the increase in oxygen consumption associated with load carriage. The $\mathrm{VO}_{2}$ increase from unloaded to loaded walking for warm ambient temperatures is similar to that of very cold temperatures. However, the second hypothesis can be accepted, as a decrease in temperature elicited an increase in oxygen uptake. Prolonged exposure to the cold also saw $\mathrm{VO}_{2}$ significantly increase, with the second bout of unloaded exercise producing significantly higher $\mathrm{VO}_{2}$ in sub-zero temperatures than the first. The hypothesis regarding SL can also be rejected, as although increasing gradient elicited greater SL, increasing load and decreasing temperature did not interact with gradient to give a greater SL. SL decreased in colder temperatures, with load having no effect on SL.

Future research could focus on the magnitude and time course of the effect of prolonged exposure in the cold on increasing $\mathrm{VO}_{2}$ to establish if subsequent loaded periods would produce further significantly increases in $\mathrm{VO}_{2}$.

\section{Compliance with ethical standards}

Conflict of interest The authors declare that they have no conflict of interest.

Open Access This article is distributed under the terms of the Creative Commons Attribution 4.0 International License (http:// creativecommons.org/licenses/by/4.0/), which permits unrestricted use, distribution, and reproduction in any medium, provided you give appropriate credit to the original author(s) and the source, provide a link to the Creative Commons license, and indicate if changes were made.

\section{References}

American College of Sports Medicine (2013) ACSM guidelines for exercise testing and prescription. 9th edn. Lippincott Williams \& Wilkins, Baltimore

Cannon B, Nedergaard J (2004) Brown adipose tissue: function and physiological significance. Physiol Rev 84(1):277-359

Castellani JW, Tipton MJ (2016) Cold stress effects on exposure tolerance and exercise performance. Compr Physiol 6:443-469

Doubt TJ (1991) Physiology of exercise in the cold. Sports Med 11(6):367-381

Faghy M, Brown P (2014) Thoracic load carriage-induced respiratory muscle fatigue. Eur J Appl Physiol 114(5):1085-1093

Fellin RE, Seay JF, Gregorczyk KN, Hasselquist L (2016) Spatiotemporal parameters are not substantially influenced by load carriage or inclination during treadmill and overground walking. J Hum Kinet 50(1):27-35

Folland JP, Rowlands DS, Thorp R, Walmsley A (2006) Leg heating and cooling influences running stride parameters but not running economy. Int J Sports Med 27(10):771-779

Givoni B, Goldman R (1971) Predicting metabolic energy costs. J Appl Physiol 30(3):429-433

Grenier J, Peyrot N, Castells J, Oullion R, Messonnier L, Morin JB (2011) Energy cost and mechanical work of walking during load carriage in soldiers. Med Sci Sports Exerc 44(6):1131-1140

Hainsman MF (1988) Determinants of load carrying ability. Appl Ergon 19(2):111-121

Harman, E. Hoon Han, K. Frykman, P. and Pandord, C (2000) The effects of backpack weight on the biomechanics of load carriage. (Tech. Rep. TOO-17). Natick. U.S. Army Research Institute of Environmental Medicine, MA

Ito R, Nakano M, Yamane M, Amano M, Matsumoto T (2013) Effects if rain on energy metabolism while running in a cold environment. Int J Sports Med 34(8):707-711

Jett DM, Adams KJ, Stamford BA (2006) Cold exposure and exercise metabolism. Sports Med 36(8):643-656

Kawamura K, Tokuhiro A, Takechi H (1991) Gait analysis of slope walking: a study on step length, stride width, time factors and deviation in the centre of pressure. Acta Med Okayama 45(3): 179-184

Kirtley C (2006) Clinical Gait analysis: theory and practice. Churchill Livingstone, Elsevier, London 
Knapik J, Harman E, Reynolds K (1996) Load carriage using backpacks: a review of physiological, biomechanical and medicine aspects. Appl Ergon 27(3):207-216

Kruk B, Pekkarinen H, Manninen K, Haenninen O (1991) Comparison in men of physiological responses to exercise of increasing intensity at low and moderate ambient temperatures. Eur J Appl Physiol Occup Physiol 62(5):353-357

Leroux A, Fung J, Barbeau H (2002) Postural adaptation to walking on inclined surfaces: normal strategies. Gait Posture 15(1):64-74

Levine D, Richards J, Whittle MW (2012) Whittle's gait analysis, 5 th edn. Churchill Livingstone, Elsevier, London

Li K, Ackland DC, McClelland JA, Webster KE, Feller JA, de Steiger R, Pandy MG (2013) Trunk muscle action compensates for reduced quadriceps force during walking after total knee arthroplasty. Gait Posture 38(1):79-85

Lloyd R, Cooke CB (2000) The oxygen consumption associated with unloaded walking and load carriage using two different backpack designs. Eur J Appl Physiol 81(6):486-492

Lloyd R, Cooke C (2011) Biomechanical differences associated with two different load carriage systems and their relationship to economy. Hum Mov 12(1):65-74

Lloyd A, Havenith G (2016) Interactions in human performance: an individudal and combined stressors approach. Temperature 3(4):514-517

McIntosh AS, Beatty KT, Dwan LN, Vickers DR (2006) Gait dynamics on an inclined walkway. J Biomech 39(13):2491-2502

Nedergaard J, Bengtsson T, Cannon B (2007) Unexpected evidence for active brown adipose tissue in adult humans. Am J Physiol Endocrinol Metabol 293(2):E444-E452

Nedergaard J, Bengtsson T, Cannon B (2011) Three years with adult human brown adipose tissue. Ann N Y Acad Sci 1212(1):E20-E36

Oksa J (2002) Neuromuscular performance limitations in the cold. Int J Circumpolar Health 61(2):154-162

Oksa J, Kaikkonen H, Sorvisto P, Vaappo M, Martikkala V, Rintamäki $\mathrm{H}$ (2004) Changes in maximal cardiorespiratory capacity and submaximal strain while exercising in cold. $J$ Therm Biol 29(7-8):815-818

OnTop Ltd (2014) Monte Rosa Peaks Traverse. [Online] Canada; OnTop Ltd. Available from: http://www.ontopmountaineering. com/monterosa.php. Accessed 02 Dec 2014.

Ouellet V, Labbé S, Blondin D, Pheonix S, Guérin B, Haman F, Turcotte E, Richard D, Carpentier A (2012) Brown adipose tissue oxidative metabolism contributes to energy expenditure during acute cold exposure in humans. The Journal of Clinical Investigation 122(2):545-552

Parsons K (2003) Human thermal environments, 2nd edn. Taylor and Francis, London
Patton JF, Vogel JA (1984) Effects of acute cold exposure on submaximal endurance performance. Med Sci Sports Exerc 16(5):494-497

Phillips DB, Ehnes CM, Stickland MK, Petersen SR (2016a) The impact of thoracic load carriage up to $45 \mathrm{~kg}$ on the cardiopulmonary response to exercise. Eur J Appl Physiol, pp 1-10

Phillips DB, Stickland MK, Lesser IA, Petersen SR (2016b) The effects of heavy load carriage on physiological responses to graded exercise. Eur J Appl Physiol 116(2):275-280

Pugh L. G.(1967) Cold stress and muscular exercise, with special reference to accidental hypothermia. Br Med J 2(5548):333-337

Quesada PM, Mengelkoch LJ, Hales RC, Simon SR (2000) Biomechanical and metabolic effects of varying backpack loading on simulated marching. Ergonomics 43(3):293-309

Ramanathan NL (1964) A new weighting system for mean surface temperature of the human body. J Appl Physiol 19(3):531-533

Renburg J, Sandsund M, Wiggen, Ø. N, Reinertsen RE (2014) Effect of ambient temperature on female endurance performance. J Therm Biol 45:9-14

Sandsund M, Sue-Chu M, Helgerud J, Reinertsen RE, Bjermer L (1998) Effect of cold exposure ( -15 degrees C) and salbutamol treatment on physical performance in elite nonasthmatic crosscountry skiers. Eur J Appl Physiol Occup Physiol 77(4):297-304

Sandsund M, Saursaunet V, Wiggen, Ø., Renberg J, Færevik H, Beekvelt M (2012) Effect of ambient temperature on endurance performance while wearing cross-country skiing clothing. Eur J Appl Physiol 112(12):3939-3947

Santee, W., Blanchard, L., Small, M., Gonzalez, J., Matthew, W. and Speckman, K. (2001) The impact of load and grade in energy expenditure during load carriage, Part II: Field study. US Army Medical Research and Material Command, pp 1-26

Simpson KM, Munro BJ, Steele JR (2011) Effect of load mass on posture, heart rate and subjective responses of recreational female hikers to prolonged load carriage. Appl Ergon 42(3):403-410

Singh T, Koh M (2009) Effects of backpack load on spatiotemporal parameters and trunk forward lean. Gait Posture 29(1):49-53

Spitz MG, Kenefick RW, Mitchell JB (2014) The effects of elapsed time after warm-up on subsequent exercise performance in a cold environment. J Strength Cond Res 28(5):1351-1357

Timmons BA, Araujo J, Thomas TR (1985) Fat utilization enhanced by exercise in a cold environment. Med Sci Sports Exerc 17(6):673-678

Wakabayashi H, Oksa J, Tipton M (2015) Exercise performance in acute and chronic cold exposure. J Phys Fit Sports Med 4(2):117-185 